\title{
Le CaV se re-volte
}

Lucette Pelletier, Marc Moreau

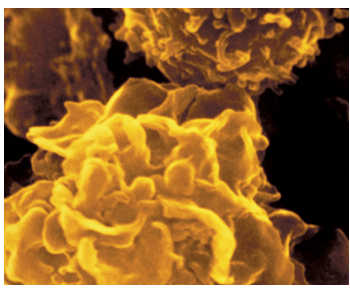

GDRE 731, $\mathrm{Ca}^{2+}$ toolkit coded proteins as drug targets in animal and plant cells, Toulouse, Université Paul Sabatier, 118 , route de Narbonne, 31062 Toulouse, France.

Alain Trautmann soulève plusieurs questions impormarc.moreau@univ-tlse3.fr tantes dans sa réponse à notre article sur le rôle des canaux dépendants du voltage dans la régulation du signal calcium dans la sous-population Th2 des lym-

$(\rightarrow)$ Voir dans ce numéro l'artcile de V. Robert et al., page 773 et la réponse d'A. Trautmann page 781 phocytes $\mathrm{T}(\rightarrow)[1,2]$.

Sauf à considérer qu'il existe un biais expérimental dans les données, l'ensemble des résultats indique un rôle de Cavl.2 et Cav1.3 dans la régulation du signal calcium dans la population de lymphocytes Th2 qui serait absent dans la population Thl. Pour mémoire, rappelons que :

- dans les lymphocytes Th2, la réponse calcique, la transcription des gènes de cytokines et la production de cytokines sont inhibées par une dihydropyridine (DHP) antagoniste des canaux Cavl, et ce de manière dépendante de la dose. II n'y a pas d'effet sur la réponse calcique dépendante de la thapsigargine ou de l'ionomycine;

- une DHP agoniste induit un influx de calcium et l'expression des gènes de cytokines dans les Th2 et pas dans les Thl ;

- la transfection des Th2 avec des oligonucléotides antisens spécifiques de Cavl.2 ou Cavl.3 réduit de moitié l'expression du canal ciblé sans effet sur d'autres molécules importantes dans l'homéostasie du calcium intracellulaire. La transfection avec ces antisens inhibe fortement l'augmentation de $\left[\mathrm{Ca}^{2+}\right] \mathrm{i}$ qui survient en réponse à l'activation du TCR et la production de cytokines par les Th2. Ces antisens ne modifient pas la réponse à l'ionomycine ou à la thapsigargine. II n'y a pas d'effet sur les Thl ;

- les Th2 (une population impliquée dans le développement de l'asthme allergique) transfectés avec les oligonucléotides CavlAS perdent leur capacité à induire un asthme quand ils sont transférés chez un hôte exposé à l'antigène par voie aérienne, alors que les Thl traités de la même façon gardent leur capacité à induire une pathologie respiratoire.

On peut imaginer que la dihydropyridine antagoniste pourrait agir via les canaux Kvl.3. Cependant, le résultat avec la DHP agoniste ne peut s'expliquer par une interaction avec ce type de canal et une induction d'un signal calcium.

Les résultats avec les oligonucléotides antisens (Cavl.2 et Cav1.3), comme le souligne Alain Trautmann, montrent que Cavl.2 et Cavl.3 agissent au moins en tant que modulateurs de la réponse calcique.

L'entrée du calcium est modulée via différentes familles de canaux calciques répondant à différents stimulus (dépolarisation, médiateurs chimiques et peptidiques, messagers intracellulaires, déplétion des stocks calciques internes). Ces canaux sont inclus dans des complexes macromoléculaires constitués de plusieurs protéines. C'est le complexe supramoléculaire qui est porteur de la fonction et non un seul des éléments du complexe. On peut aisément imaginer que la cellule utilise les différentes protéines mises à sa disposition dans la «boite à outil » du signal calcium (le calcium toolkit de M. Berridge) pour créer des complexes capables de réaliser une fonction particulière dans un environnement cellulaire défini.

Dans cet assemblage supramoléculaire, où passe l'ion calcium et quelle est l'entité qui joue physiquement le rôle de canal sont effectivement des questions ouvertes.

Si la sous-unité alpha n'est pas physiquement le canal, cela signifie qu'une même protéine pourrait avoir des rôles différents selon le contexte. Cela a déjà été décrit dans les cellules procaryotes, mais ce serait une information de première importance dans les cellules eucaryotes.

Ainsi, selon le complexe moléculaire dans lequel ils sont impliqués, les canaux calciques Cavl dépendants du voltage ne seraient plus ni dépendants du voltage, ni éventuellement canaux. L'aphorisme pionnier de François Jacob «la nature bricole » serait ici parfaitement illustré. 
II reste à expliciter le rôle physique des Cavl dans la fonction de modulation du signal calcium des Th2. II reste aussi à admettre que les sous-unités protéiques alpha de Cavl.2 et Cavl.3 peuvent s'adapter pour être des rouages d'un dispositif biologique ayant pour fonction la modulation de la signalisation calcique, et ce sans que leurs conformations soient modulées par un changement de potentiel, mais par un autre type de stimulus. $\diamond$

\section{$\mathrm{CaV}$ rebels}

\section{LIENS D'INTÉRÊT}

Les auteurs déclarent n'avoir aucun lien d'intérêt concernant les données publiées dans cet article.

\section{RÉFÉRENCES}

1. Robert V, Triffaux $\varepsilon$, Savignac M, Pelletier L. La signalisation calcique dans les lymphocytes T. Med Sci (Paris) $2012 ; 28: 773-9$.

2. Trautmann $A$. Les canaux calciques dépendants du voltage associés aux lymphocytes sont non fonctionnels. Med Sci (Paris) 2012 ; 28 : 781-2.

\section{Collection L'Actualité Chimique-Livres}
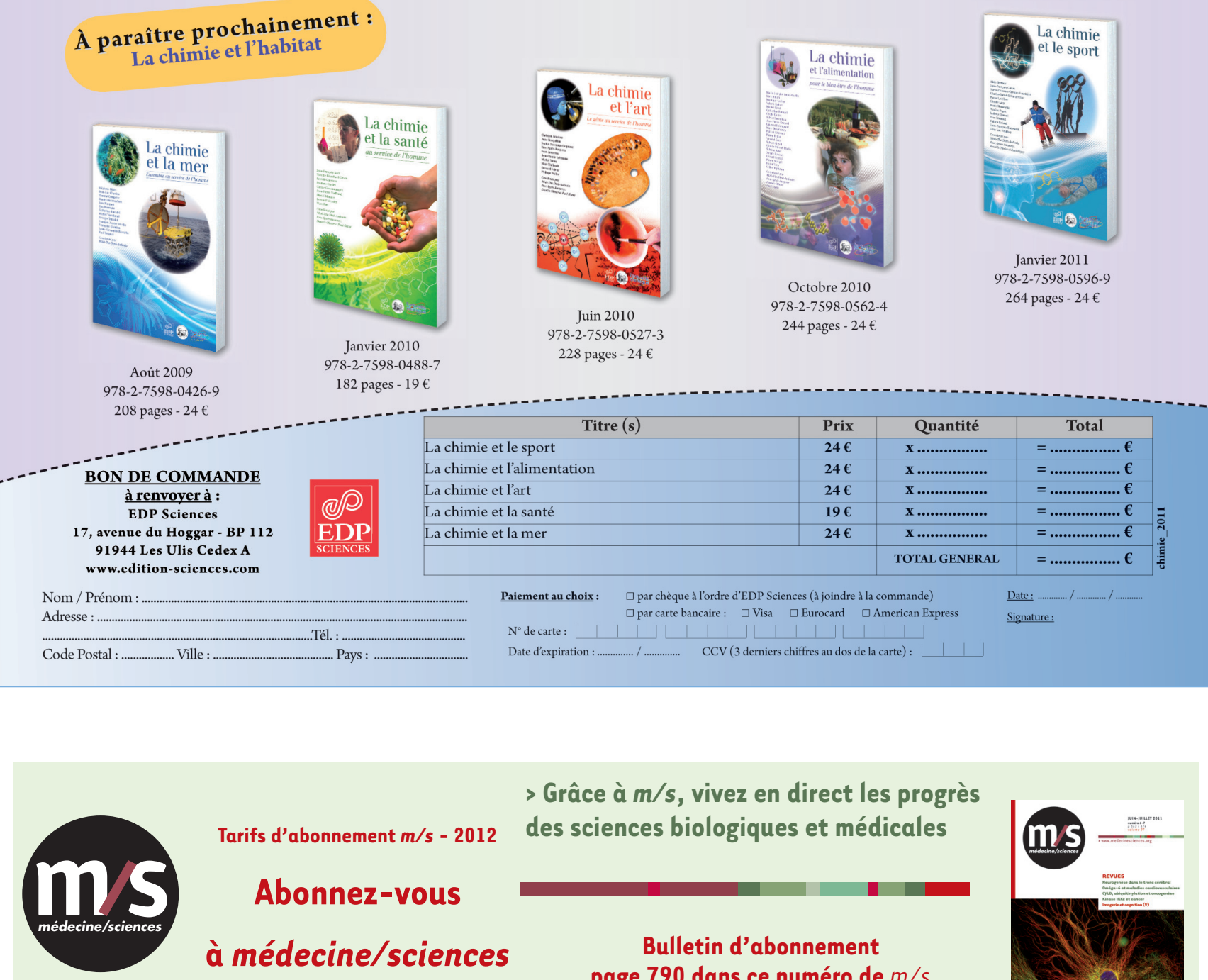

$>$ Grâce à $m / s$, vivez en direct les progrès

Tarifs d'abonnement $m / s-2012$

des sciences biologiques et médicales

Abonnez-vous

à médecine/sciences

\section{Bulletin d'abonnement} page 790 dans ce numéro de $\mathrm{m} / \mathrm{s}$

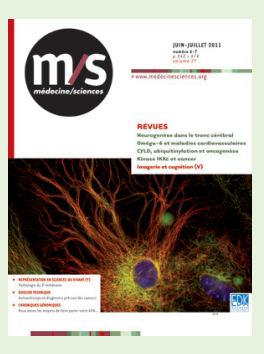

